\title{
THE PLEUROPNEUMONIA GROUP OF ORGANISMS AND THEIR SIGNIFICANCE IN GENITAL INFECTION*
}

BY

\author{
D. G. ff. EDWARD \\ Wellcome Research Laboratories, Beckenham, Kent
}

The recent recognition that in many parts of the world a considerable proportion of cases of urethritis are not due to the gonococcus has interested venereologists in their aetiology. Organisms of the pleuropneumonia group have been isolated from a number of men suffering from non-specific urethritis. Similar organisms have been isolated from a high proportion of women, including the apparently healthy, so that it has remained doubtful whether these organisms are in fact causing the disease. Isolations from the genital tract continue to be reported without providing fresh evidence regarding the significance of the organisms. It would thus seem a suitable moment to survey the available information and to suggest lines along which future inquiries might usefully be made with the idea of establishing whether or not organisms of the pleuropneumonia group cause genital infection in man and animals.

Future investigations should be based on a knowledge of the properties of this group of organisms. Since many persons, including even bacteriologists, are not familiar with these organisms, this review begins with a brief statement of their nature and properties. This is particularly necessary owing to the confusion which has arisen regarding their relationship to bacteria.

\section{The Pleuropneumonia Group of Organisms}

The filterable agent causing contagious bovine pleuropneumonia was cultivated in an artificial medium by Nocard and Roux (1898). Borrel and others (1910) demonstrated it microscopically and described its peculiar morphology. For many years it remained unique among micro-organisms and was usually classed with the viruses. Agalactia of sheep was shown in 1923 to be caused by an organism similar in morphology and cultural behaviour, but another 10 years elapsed before

\footnotetext{
* Received for publication February 19, 1952.
}

other similar organisms were isolated, and the fact was recognized that all belonged to one group. This recent phase began with the isolation by Klieneberger (1935) of a pleuropneumonia-like organism from a culture of Streptobacillus moniliformis. Other strains were later isolated directly from animals. For further details the excellent review by Sabin (1941) should be consulted.

Several of the first strains to be isolated were encountered accidentally during the passage of viruses in laboratory animals and thus it happened that the methods of study applied then were largely those used to examine viruses. Their curious morphology was also extensively studied (Klieneberger and Smiles, 1942; Dienes, 1945). It is perhaps unfortunate that equal attention has not been paid to their metabolism and that they have been insufficiently examined by the usual bacteriological methods, so that they are too often regarded as curiosities. Technical difficulties have contributed to this attitude but their cultivation has now been made easier (Edward, 1950b).

General Characteristics. - The organism of bovine pleuropneumonia is the type species of what is probably a large group of organisms with many properties in common. Although the smallest elements pass bacteriological filters, growth occurs on artificial media and the colonies are highly characteristic, especially in the downgrowth into the medium producing a central spot. The organisms themselves are decidedly pleomorphic-rings, globules, filaments, and minute elementary bodies being visible in fluid cultures. Stained preparations of whole colonies on a solid medium are characteristic (Klieneberger and Smiles, 1942). Pleomorphism appears to result from the absence of a cell wall, such as bacterial cells possess (Smith, Hillier, and Mudd, 1948). Life cycles for these organisms have been described (Klieneberger and Smiles, 1942). They divide not only by binary 
fission, but by multipolar germination. They are extremely, if not completely, resistant to the bacteriostatic action of penicillin.

The whole group can be subdivided into two subgroups : one sub-group contains strains believed to be saprophytic which will grow on simple media not enriched with serum, and the other sub-group includes some definitely pathogenic strains producing natural disease in animals, and others whose pathogenicity is doubtful. A nomenclature has not yet been agreed upon and would be premature until more is known about the taxonomic relationship of the organisms to the ordinary bacteria. Meanwhile a number of species can be recognized and distinguished by their cultural, biochemical, and pathogenic properties, each species being distinct antigenically. They may be referred to as " organisms of the pleuropneumonia group"; "pleuropneumonialike organisms" (PPLO) is shorter, but is difficult to translate into other languages and draws an unnecessary distinction between the type species and all the other members of the group. Sometimes the term " L-organisms" is used, because Klieneberger called her original strains L1, L2, L3, and so on. This term is unfortunate since it only refers to a provisional system of labelling of strains isolated by one worker; its use has moreover led to much confusion, because the L1 organism is now recognized to be the variant of a bacillus, whereas L3, L4, and L5 are members of the pleuropneumonia group isolated directly from animals.

Relationship of Organisms of the Pleuropneumonia Group to the L-Phase of Bacteria.-Colonies resembling those of organisms of the pleuropneumonia group have been noted in cultures of many different bacterial species, especially after exposure to unfavourable conditions. Subculture from these colonies has sometimes been possible, and a pleuropneumonia-like form or L-phase was isolated for study, although there was usually a tendency to revert to the bacillary form. It is now agreed that the L-phase is a variant of the bacterium or a stage in its life-cycle (Dienes, 1947a ; Klieneberger-Nobel, 1949). Colonies of the L-phase closely resemble those of pleuropneumonia-like organisms in stained preparations, and have the same tendency to grow into the medium forming a central spot. However, observations of three L-phase cultures showed that they could be distinguished from true pleuropneumonia-like organisms by examining their colonies unstained, using a dissecting microscope (Edward, 1950b; and unpublished observations). The Lphase colonies were coarser and more opaque, having many of the appearances of a bacterial colony. Even in morphology certain differences were noted. From the published descriptions other L-phase cultures also differed in colonial appearances from true pleuropneumonia-like organisms. There would therefore seem to be less risk of mistaking an organism in the L-phase for an organism of the pleuropneumonia group than has been suggested (Tulasne, 1951). Confusion of the one type of organism with the other, however, has probably occurred where identification has depended on examining stained preparations of colonies (Salaman, 1946).

The presence of penicillin in culture media can induce bacteria to form L-type colonies (Dienes, 1947b), but the L-phase is difficult or impossible to subculture and usually tends to revert to the bacillary form in the absence of penicillin. The L-phase retains most of the biochemical properties of the bacillary phase; for instance, cultures of the L-phase of Proteus vulgaris possess the characteristic smell.

Although organisms of the pleuropneumonia group may have developed from bacteria in the course of evolution, the evidence suggests that they exist now as independent organisms and are not merely the L-phase of bacteria developed under the conditions of cultivation. The infectious agent of contagious bovine pleuropneumonia is filterable while still in the animal tissues ; and the organism causing infectious catarrh of mice is visible inside infected cells as minute cocco-bacillary bodies (Edward, 1947a).

Cultivation.-Bacteriological study has been retarded by difficulties in cultivation. The nutritional requirements of these organisms are exacting, and their growth is slow and scanty, so that they are easily overgrown by contaminating bacteria. However, their isolation from materials contaminated by bacteria and their maintenance in pure culture have been aided by using selective media. Pleuropneumonia-like organisms are more resistant than bacteria to a number of bacteriostatics. Edward (1947b) described a medium containing penicillin and thallium acetate ; Bushby (see Harkness, 1950) employed polymyxin and sulphathiazole in addition; Smith and Morton (1951b), wishing to avoid penicillin, found a combination of crystal violet and potassium tellurite satisfactory.

For adequate growth, a rich basal medium must be used, further enriched with serum or ascitic fluid. Smith and Morton (1951a, b) used a fraction of serum believed to contain a specific growth factor, instead of whole serum, and reported good results, but Edward and Fitzgerald (1951b) reached 
different conclusions in their attempts to identify the growth factor in serum. Provided that special selective media are used and that incubation is maintained in a moist atmosphere, cultivation of these organisms is not difficult, and they can be studied by many of the usual bacteriological methods. Suspensions for serological study can be obtained by collecting the centrifuged deposits from sufficiently large volumes of broth cultures.

An organism can most readily and certainly be identified as a member of the pleuropneumonia group by observing its colonies with a dissecting microscope using slightly oblique transmitted light ; demonstration of its characteristic morphology supplies confirmation when necessary. Colonies of the various members of the group differ little from each other, but can be easily distinguished from those of bacteria. As already suggested, it is by colonial appearances that the organisms can most easily be distinguished from the L-phase of bacteria.

\section{Isolation from the Human Genital Tract}

Dienes and Edsall (1937) reported the isolation in pure culture of an organism of the pleuropneumonia group from a Bartholin's abscess. In subsequent reports, Dienes and his associates (Dienes, 1940 ; Dienes and Smith, 1942 ; Dienes and others, 1948) showed that pleuropneumonialike organisms could frequently be isolated from both the male and female genital tracts, and they suggested that these might be the cause of infections of otherwise unknown aetiology. Their observations aroused interest, as wartime experience suggested that a considerable proportion of cases of urethritis in the male were not due to the gonococcus. Confirmation of the presence of pleuropneumonia-like organisms in the human genital tract was soon obtained, although its significance remained uncertain.

The earlier reports suggested that in the male there was a fairly close association between the presence of the organisms and evidence of infection. In an unselected series of urethral cultures for pleuropneumonia-like organisms from men attending a urological clinic 8 per cent. were positive (Dienes and others, 1948), whereas 20 per cent. were found to be positive among cases of non-specific urethritis (Beveridge, Campbell, and Lind, 1946). Harkness and Henderson-Begg (1948), who classified their cases into acute bacterial urethritis and subacute urethritis of the Waelsch type, found 50 per cent. positive in the first group and 38 per cent. in the second. Urethral cultures from 67 students were negative (Beveridge and others, 1946), and there were no positive isolations from another group of fifty healthy men (Harkness and Henderson-Begg,
1948). There were four positives among 28 apparently normal men examined by Salaman (1946), but as Harkness (1950) pointed out, adequate clinical examinations were not made to exclude the possibility of the existence of a mild infection in the positive cases. Harkness himself found 10 per cent. positive in a control series of 68 apparently normal men. In the most recent series reported the proportion of positive isolations (16 per cent.) obtained from the normal controls was not significantly different from the proportion from cases of non-specific urethritis (Melén and Linnros, 1952).

Positive isolations were more frequent in the female. Among 300 consecutive cultures made from the cervix, 26 per cent. were positive (Randall, Stein, and Ayres, 1950). The percentage of positives was greater ( 51 per cent.) among those with evidence of genital infection than among those whose pelvic organs were normal or affected only by non-inflammatory conditions ( 17 per cent.). In another series, pleuropneumonia-like organisms were isolated from the cervix from 26 per cent. of patients with genital infection, there being no positive isolations from fifteen women regarded as healthy (Harkness and Henderson-Begg, 1948). These results suggest that, although organisms have been isolated from the cervices of women apparently free of infection, they are commoner in those with evidence of infection. Klieneberger-Nobel (1945) confirms this ; she found 40 per cent. positive among women attending a venereal disease clinic, 33 per cent. positive from a gynaecological clinic, and 14 per cent. from an antenatal clinic. Pleuropneumonialike organisms, often in pure culture, were isolated from the post-partum uterus in 15 per cent. of 112 examinations (Schaub and Guilbeau, 1949). Sometimes, when it has been possible to obtain cultures from the female contacts of men with non-specific urethritis, positive isolations were made from both the man and woman (Harkness and HendersonBegg, 1948 ; Morton, Smith, and Leberman, 1951).

When organisms of the pleuropneumonia group were isolated from urethral and cervical swabs, other pathogens were usually absent, but sometimes the gonococcus or Trichomonas vaginalis was also present. Harkness and Henderson-Begg (1948) isolated pleuropneumonia-like organisms from only 9 per cent. of men with acute gonorrhoea ; Salaman (1946) reported a much higher proportion of isolations from cases of gonorrhoea, but he examined only stained impression films of his cultures and thus probably regarded as colonies of pleuropneumonia-like organisms areas where gonoccocal colonies had undergone pleomorphic degeneration, 
or change to the L-phase. Salaman suggested that the pleuropneumonia-like organisms might be a stage in the life-cycle of the gonococcus, but there seems little doubt that the organisms isolated by other workers were true members of the pleuropneumonia group, and were unrelated to the gonococcus.

Many of the patients from whom organisms of the pleuropneumonia group were isolated suffered from complications known to follow non-specific urethritis and cervicitis. Pure cultures were sometimes obtained from the prostatic secretions and urine in cases of prostatitis and cystitis and from pus from various forms of pelvic abscess in both males and females (Dienes and others, 1948 ; Harkness, 1950 ; Randall and others, 1950). Now that penicillin treatment has become common, it must be remembered that isolation in pure culture from the pus of an abscess does not necessarily imply that the organism isolated was the cause of the abscess. This organism may have been present as a saprophyte in an abscess caused by another organism, which has been destroyed later by the penicillin.

Arthritis as a complication has aroused particular interest because several members of the pleuropneumonia group produce arthritis in animals. Pleuropneumonia-like organisms were isolated from some, but not all, patients with arthritis or with Reiter's syndrome (Harkness and Henderson-Begg, 1948 ; Patočka and Suchanová, 1950), and they were even isolated from the synovial joint fluid in several cases of Reiter's syndrome (Dienes and others, 1948 ; Kuzell and Mankle, 1950).

Organisms of the pleuropneumonia group have been isolated not only from men with non-specific urethritis who had contracted the disease by sodomy, but also from the anal canal of men who were their contacts (Harkness and Henderson-Begg, 1948). They have also been isolated from the rectum and anal canal of normal individuals (Harkness, 1950). Moreover, reports have recently been made of their isolation from cases of human infection, affecting sites other than the genital tract: they have been isolated from two brain abscesses (Paine and others, 1950 ; Carlson, Spector, and Douglas, 1951), from two cases of Henoch-Schönlein purpura (Carlson and others, 1951), and from cases of pneumonia in children (Grünholz, 1950). One of the brain abscesses had resulted from an injury, a tobacco-pipe having penetrated into the brain, and one case of purpura followed a human bite. These histories suggest that the organisms had come from the mouth and Smith and Morton (1951b) have subsequently reported the isolation of pleuro- pneumonia-like organisms from the throat and mouth of normal individuals. These non-genital strains were not studied sufficiently to know whether they were the same as the genital strains.

Cellular Inclusions. - There is evidence that at least a certain number of cases of non-specific urethritis and cervicitis, as well as of conjunctivitis, are due to a virus giving rise to characteristic cytoplasmic inclusion bodies. Intracellular inclusions associated with pleuropneumonia-like organisms have also been described. Johnston and McEwin (1945) observed cocco-bacillary cytoplasmic inclusions in two cases of non-specific urethritis from which pleuropneumonia-like organisms were isolated. Williams (1946) reported similar inclusions, visible in the large epithelial cells but not in the leucocytes. Attempts have been made to classify cases of non-specific urethritis into groups, according to whether they were caused by a virus or were associated with the presence of pleuropneumonia-like organisms, by examining stained films of exudate for inclusion bodies (Harkness, 1950 ; Durel and others, 1950). It was considered that the inclusions in the two types of infection were different and could be distinguished from artefacts. Further observations are necessary to confirm these opinions and to establish whether characteristic inclusions are in fact produced by pleuropneumonialike organisms. Attention should also be paid to the leucocytes, using a stain such as methylene blue which does not stain the normal granules. The discharge is purulent and many species of the pleuropneumonia group are pyogenic. Moreover cocco-bacillary inclusions in leucocytes were a noticeable feature of an infection of mice due to a pleuropneumonia-like organism (Edward, 1947a). It must, however, be remembered that the demonstration of organisms in cells, does not prove their pathogenicity.

Chemotherapy.-Evidence about the aetiology of non-specific urethritis may possibly be obtained by comparing the clinical response to chemotherapeutic drugs with the sensitivity of pleuropneumonialike organisms to the drugs in vitro. As already suggested, more than one infective agent may cause the disease. If these agents have different drug sensitivities, a means would be available for differentiating between cases and for classifying them, but caution would be necessary in judging response to treatment. Non-specific urethritis is variable in its severity, the discharge being sometimes so slight as to be hardly noticeable. It may clear up spontaneously, although relapse is not uncommon. Remissions and spontaneous cure also 
occur with metastatic complications, such as arthritis.

Pleuropneumonia-like infections of rodents have responded to organic gold compounds, such as myocrisin (Powell and Rice, 1944), to streptomycin (Powell, Jamieson, and Rice, 1946), aureomycin (Kuzell, Gardner, and Fairley, 1949), and terramycin (Kuzell and Mankle, 1950). No effect was obtained with penicillin (Powell and Rice, 1944), the sulphonamides (Findlay, Mackenzie, and MacCallum, 1940), and cortisone (Kuzell and Mankle, 1950). The extreme in vitro resistance of all members of the pleuropneumonia group to penicillin has been noted. A number of chemotherapeutic drugs have been tested for ability to inhibit in vitro human genital strains of the pleuropneumonia group. All were very resistant to sulphonamides (Beveridge, 1943). Some strains were inhibited by $50 \mu \mathrm{g} / \mathrm{ml}$. of aureomycin (Hatch, 1949), but others were resistant to $200 \mu \mathrm{g} / \mathrm{ml}$. (Leberman, Smith, and Morton, 1950). Strains also varied in their sensitivity to chloramphenicol; some were inhibited by $15 \mu \mathrm{g} / \mathrm{ml}$, and others resisted 100 $\mu \mathrm{g} / \mathrm{ml}$. (Leberman and others, 1950). The majority of strains were inhibited by $5 \mu \mathrm{g} / \mathrm{ml}$. streptomycin (Leberman and others, 1950; Bushby, 1952), although 15 to $25 \mu \mathrm{g} / \mathrm{ml}$. was needed to inhibit a few strains (Hatch, 1949). Three strains were inhibited by $2 \mu \mathrm{g} / \mathrm{ml}$. terramycin (Bushby, 1952).

It would be expected from these results that, if organisms of the pleuropneumonia group caused infections of the genital tract, such infections would be most likely to respond to streptomycin or terramycin, though some cases might prove resistant even to these. A rapid development of resistance to streptomycin, both in vitro and in vivo, was noted with a strain of pleuropneumonia-like organism isolated from a human brain abscess (Paine and others, 1950).

A number of reports have appeared of the effects of chemotherapy on non-specific urethritis and its complications, but no attempt has yet been made to differentiate between cases according to the response to treatment. Further observations would be of interest, the response to treatment being correlated with clinical and bacteriological findings in a large series of cases.

Non-specific urethritis does not usually respond to penicillin, nor to sulphonamides (Harkness, 1950), although a few cases are apparently improved by drugs of the latter group. Good results have been reported with streptomycin (Dienes and others, 1948 ; Harkness, 1950) and aureomycin (Willcox and Findlay, 1949 ; Brown and others, 1949), and two cases of Reiter's syndrone were improved by myocrisin (Willcox, Findlay, and Henderson-Begg, 1947). It is interesting that treatment of Trichomonas vaginalis infections with stovarsol has caused the disappearance of pleuropneumonia-like organisms when they were also present (Salaman, 1946), because it has a preventive and curative action in agalactia of sheep (Bridré and others, 1928).

\section{Isolation from the Genital Tract of Animals}

From Cattle.-Organisms of the pleuropneumonia group have been shown to inhabit the genital tract of cattle (Edward, Hancock, and Hignett, 1947 ; Diernhofer, 1951). They were isolated only from cows and heifers which were themselves suffering from cervicitis or belonged to herds with breeding difficulties of apparently infective aetiology. They were not isolated from maiden heifers. They were found more frequently in the semen of bulls, and, although never demonstrated in young bulls not previously used for service, were often isolated from apparently healthy animals with good breeding records. The organisms were usually isolated from vaginal discharges in the absence of other known pathogens, but sometimes another organism, such as Corynebacterium pyogenes or Vibrio foetus, was present, just as pleuropneumonia-like organisms have occasionally been found in human discharges together with the gonococcus.

Two findings in cattle are of general interest :

(a) Examination of the bovine genital strains showed that they belonged to two different species of the pleuropneumonia group, provisionally designated as ' $P$ ' and ' $S$ ' (Edward, 1950a). Only the $P$ strains were regarded as possibly pathogenic; the $S$ strains were probably saprophytes and reached the cultures as contaminants.

(b) At first isolation the majority of P strains needed a specific growth factor found in hog gastric mucin. When the semen of certain bulls was plated on the routine medium, no growth was obtained, but colonies of pleuropneumonia-like organisms appeared when the semen was plated on the same medium with the addition of hog gastric mucin. In cultures of vaginal discharges from infected cows colonies often appeared only under the streaks of mucus; subculture was difficult or impossible except in the presence of mucin. Adaptation of such strains took place rapidly so that after a few subcultures they grew well without mucin. Strains differed in their need for mucin at first isolation. Only one of twenty strains did not need mucin ; most strains grew to some extent without it, but their growth was improved by it.

These findings demonstrate the difficulties attending cultivation of the pleuropneumonia group, particularly the danger in assuming that negative cultures exclude the presence of the organisms. They may be present in material and yet fail to 
grow on a medium which is perfectly satisfactory for growing stock cultures.

There is some evidence to suggest that the $P$ strains are pathogenic and capable of causing a mild inflammation of the genital tract, predisposing to infertility, but experimental proof has not been obtained. The inoculation of cultures into the uterus of heifers did not produce disease. This does not prove that the organisms are non-pathogenic, because pathogenicity may be lost rapidly during cultivation. It has already been shown that artificial cultivation changes an organism so that it no longer needs the mucin factor. Although need for the mucin factor cannot be definitely correlated with virulence, it has sometimes been noted that strains isolated from herds where there was the greatest suggestion that the organisms were producing disease were particularly dependent on mucin. A sample of vaginal discharge from a cow in such a herd produced cervicitis when inoculated into the uterus of a heifer, and the condition was passaged to a second heifer. Cervicitis was similarly set up in another heifer by inoculating semen containing pleuropneumonia-like organisms. Although in these experiments organisms of the pleuropneumonia group were present in the materials inoculated, and also in large numbers in the discharges from the infected heifers, their pathogenicity was not proved because some other pathogen may also have been present unrecognized.

From Dogs.-At least three different species of the pleuropneumonia group have been isolated from the genital tract of dogs (Edward and Fitzgerald, 1951a), but nothing definite is known about their pathogenicity. The organisms were first isolated from the semen of a dog under observation for epididymitis and infertility, who had apparently infected a second dog through a bitch with whom both dogs had been mated. Further observations on pathogenicity could not be made owing to the frequency with which organisms could be isolated from semen samples and vaginal swabs. Sometimes colonies of three different species were recognized in a culture from one swab by their slightly differing appearances. Now that the identification of the different species has been confirmed serologically, an inquiry into the possible association of each of the species with genital infection might usefully be made. It should be noted that isolations of two of the three species were obtained from the throat as well as from the genital tract.

\section{Serological Investigations}

Each species of the pleuropneumonia group appears to be distinct antigenically. The two species isolated from the genital tract of cattle and the three species from the canine genital tract were shown by agglutination and complement-fixation tests to be unrelated to each other (Edward, 1950a ; Edward and Fitzgerald, 1951a). There were minor serological differences between strains, suggesting the existence of different races.

One strain isolated from the human genital tract was found to be serologically unrelated to several members of the pleuropneumonia group isolated from rodents (Warren and Sabin, 1942). Only one attempt to find out whether all the human genital strains are serologically the same has been reported ; the five strains examined appeared to be closely similar (Norman, Saslaw, and Kuhn, 1950). A larger series of strains is at present being studied in this laboratory and the preliminary results show the existence of different serological types.

Agglutinins were not detected in the sera of patients from whom pleuropneumonia-like organisms were isolated (Harkness and Henderson-Begg, 1948 ; Norman and others, 1950). Positive agglutination with sera from four cases of Reiter's syndrome was reported, but it is doubtful whether the organism used as antigen was a member of the pleuropneumonia group (Wallerstein, Vallee, and Turner, 1946). Beveridge and others (1946) obtained many positive results in complementfixation tests on sera from cases of non-gonococcal urethritis, but there is doubt about their specificity as there were 20 per cent. positive reactions among the series of control sera from blood donors. Harkness and Henderson-Begg (1948) failed to demonstrate complement-fixing antibodies, and they could not obtain skin reactions to the intradermal inoculation of organisms. Johnston and McEwin (1945) had reported positive skin tests in two patients.

It was not possible to demonstrate agglutinins in the sera of cattle from whom $P$ strains were isolated. With the complement-fixation test a few weak positive results were obtained, but it is doubtful whether these were specific. Intradermal skin tests were negative (Edward, 1950a). Recently the finding of complement-fixing antibodies in the vaginal mucus of infected cattle against the homologous organism has been briefly reported (Szabó, 1951). Further details will be awaited with interest, as this finding suggests that further search should be made for local antibodies in the secretions in man as well as in animals.

\section{Discussion}

There is not sufficient information available to determine definitely the pathogenic significance of 
the pleuropneumonia-like organisms isolated from the human genital tract. The organisms themselves have been only imperfectly studied, most observers having been content merely to identify them as members of the pleuropneumonia group. In the one investigation reported five strains were shown to be serologically similar. Examination of the cultural, biochemical, and serological properties of a larger number of strains, isolated both from cases of infection and from healthy individuals, should be attempted in order to establish whether more than one species or type inhabits the genital tract. Two or more different species have been identified in the genital tracts of both cattle and dogs. It is also important that human non-genital strains, particularly those isolated from the mouth, should be studied to determine whether they are the same culturally and antigenically as the genital strains. Organisms could be transferred from the mouth to the genital tract by oro-genital contact.

More extensive inquiries ought to be made to determine the frequency with which pleuropneumonia-like organisms inhabit the rectum and the rectal strains should be studied to determine their relationship to the genital strains. Dieres and his colleagues (1948) noted that in a few cases with genital infection and positive cultures there was no history of venereal exposure, the condition having followed an attack of diarrhoea, and they suggested the possibility of the gastro-intestinal tract being a portal of entry. If pleuropneumonia-like organisms are common in the rectum, transfer to the genital tract would occur more easily in the female, and this might possibly explain the greater frequency of isolations from women.

Pathogenicity would be proved if disease were produced by the inoculation of cultures. It would probably be necessary to use human volunteers for such experiments, as pathogenic members of the pleuropneumonia group appear to be host-specific. Claims to have produced pneumonia in mice by intranasal inoculation of non-genital strains of human origin (Carlson and others, 1951 ; Grünholz, 1950) need confirmation, as many stocks of mice harbour pleuropneumonia-like organisms, capable of causing pneumonia (Edward, 1940, 1947a). Failure to reproduce the disease with cultures would not disprove their pathogenicity, since some organisms of this group are known to lose pathogenicity rapidly in artificial culture. Unpublished observations with an animal strain have shown that virulence was retained during repeated sub-cultivation in tissue culture, when it was lost in a cell-free medium. If tissue cultures were used to investigate pathogenicity, it would be necessary to bear in mind the possibility that a virus was also multiplying in the medium.

The available evidence is consistent with the supposition that the organisms are commensals. The fact that in the male they have more often been isolated from cases of infection may be due to their persistence in the urethra being favoured by inflammatory conditions. They presumably reach the urethra during intercourse with female carriers, and therefore in determining the frequency with which the organisms can be isolated from healthy men, observations should be limited to men living an active sex life, especially husbands of known female carriers.

The most significant indications of pathogenicity have been the isolations from the joint fluid in cases of Reiter's syndrome, and in pure culture from abscesses in patients not previously treated with penicillin. Successful isolations have only been made from one in every five cases of non-specific urethritis. It is possible that they are present more often, but are not isolated because of technical difficulties. If this be the true explanation, it is surprising that they can be isolated so easily from some cases, yet not from the others. As already suggested non-specific urethritis may be caused by more than one infective agent and pleuropneumonialike organisms may be responsible for only a minority of cases.

The great frequency of isolations from women, including the apparently healthy, has provided the most suggestive evidence for believing the organisms to be commensals. It is, however, necessary to establish whether all strains belong to the same species and serological type. Dienes and others (1948) noted cultural differences between the strains isolated from men, where there was usually evidence of infection, and the majority of those isolated from women.

Some of the complexities regarding pathogenicity are emphasized by a consideration of certain bacteria. Although most strains of Bact coli are nonpathogenic in the intestine, it is believed that gastroenteritis in children can be produced by some serological races. Although a commensal in the intestine, a strain of Bact. coli may produce inflammation in other parts of the body. Only some species of streptococci found in the throat are virulent. Pneumococci and meningococci can exist harmlessly in the upper respiratory tract, yet disease may be set up under certain conditions. Hignett (1950), who from his clinical observations concluded that the $\mathbf{P}$ strains of the pleuropneumonia group caused genital infection in cattle, suggested that infection tended to occur when some other factor, 
such as endocrine or nutritional disturbance, made the animals more susceptible. Infection may also be more easily set up by two different organisms acting together. Extrinsic factors may influence the establishment of non-specific infections in the human, and determine whether or not a man is infected by a female carrier. Infections in the male are probably almost always venereal, yet there is some evidence that the female contact may sometimes have acquired her infection non-venereally.

\section{Conclusions}

Organisms of the pleuropneumonia group have been isolated from the discharge in cases of genital infection of uncertain aetiology, and it has been suggested that the organisms may have been the cause of the infection. They have, however, also been isolated from apparently healthy individuals. Therefore they may be commensals, their presence in the genital tract being favoured by inflammatory conditions. The possibility that they may sometimes be pathogens cannot be excluded without further investigation. It is possible that pleuropneumonia-like organisms of different species or types inhabit the genital tract and that only some strains are pathogenic.

\section{REFERENCES}

Beveridge, W. I. B. (1943). Med. J. Aust., 2, 479.

- Campbell, A. D., and Lind, P. E. (1946). Ibid., 1, 179.

Borrel, A., Dujardin-Beaumetz, -, Jaentet, - , and Jouan, C. (1910). Ann. Inst. Pasteur., 24, 168.

Bridré, J., Donatien, A., and Hilbert, D. (1928). C. $R$. Acad. Sci., Paris, 187, 262.

Brown, T. McP., Wichelhausen, R. H., Robinson, L. B., and Merchant, W. R. (1949). J. Lab. clin. Med., 34, 1404.

Bushby, S. R. M. (1952). Personal communication.

Carlson, H. J., Spector, S., and Douglas, H. G. (1951). Amer. J. Dis. Child., 81, 193.

Dienes, L. (1940). Proc. Soc. exp. Biol., N. Y., 44, 468. -(1945). J. Bact., 50, 441. -(1947a). Ibid., 54, 231.

__(1947b). Proc. Soc. exp. Biol., N.Y., 64, 165.

___, and Edsall, G. (1937). Ibid., 36, 740.

_- , and Smith, W. E. (1942). Ibid., 50, 99.

__, Ropes, M. W., Smith, W. E., Madoff, S., and Bauer, W. (1948). 'New Engl. J. Med., 238, 509, 563.

Diernhofer, K. (1951). Bulletin de l'Office International des Épizooties, 36, 386. (Report to 19th Session.)

Durel, P., Roiron-Ratner, V., Siboulet, A., and Borel, L. J. (1950). Sem. Hôp. Paris, 26, 3386.

Edward, D. G. ff. (1940). J. Path. Bact., 50, 409.

-(1947a). Ibid., 59, 209.

_-(1947b). J. gen. Microbiol., 1, 238.

-_(1950a). Ibid., 4, 4.
Edward, D. G. ff. (1950b). J. gen. Microbiol., 4, 311.

—, and Fitzgerald, W. A. (1951a). Ibid., 5, 566.

,$--(1951 \mathrm{~b})$. Ibid., 5, 576 .

- , Hancock, J. L., and Hignett, S. L. (1947). Vet. Rec., 59, 329.

Findlay, G. M., Mackenzie, R. D., and MacCallum, F. O. (1940). Brit. J. exp. Path., 21, 13.

Grünholz, G. (1950). Klin. Wschr., 28, 480.

Harkness, A. H. (1950). "Non-gonococcal Urethritis." Livingstone Ltd., Edinburgh.

- , and Henderson-Begg, A. (1948). British Journal of Venereal Diseases, $24,50$.

Hatch, M. H. (1949). "A Symposium on Current Progress in the Study of Venereal Diseases ". Page 185. U.S. Public Health Service. Washington.

Hignett, S. L. (1950). Vet. Rec., 62, 654.

Johnston, G. A. W., and McEwin, J. (1945). Med. J. Aust., 1, 368.

Klieneberger, E. (1935). J. Path. Bact., 40, 93.

- , and Smiles, J. (1942). J. Hyg., Camb., 42, 110.

Klieneberger-Nobel, E. (1945). Lancet, 2, 46.

-(1949). J. gen. Microbiol., 3, 434.

Kuzell, W. C., Gardner, G. M., and Fairley, D. L. M. (1949). Proc. Soc. exp. Biol., N.Y., 71, 631.

- , and Mankle, E. A. (1950). Ibid., 74, 677.

Leberman, P. R., Smith, P. F., and Morton, H. E. (1950). J. Urol., 64, 167.

Melén, B., and Linnros, B. (1952). Acta. derm. venereol., Stockh., 32, 77.

Morton, H. E., Smith, P. F., and Leberman, P. R. (1951). Amer. J. Syph., 35, 14.

Nocard and Roux (1898). Ann. Inst. Pasteur, 12, 240.

Norman, M. C., Saslaw, S., and Kuhn, L. R. (1950). Proc. Soc. exp. Biol., N.Y., 75, 718.

Paine, T. F., Jr., Murray, R., Perlmutter, I., and Finland, M. (1950). Ann. intern. Med., 32, 554.

Patočka, F., and Suchanová, M. (1950). Čas. Lék. čes, 89, 1463.

Powell, H. M., Jamieson, W. A., and Rice, R. M. (1946). Proc. Soc. exp. Biol., N.Y., 62, 8.

- , and Rice, R. M. (1944). J. Lab. clin. Med., 29, 372.

Randall, J. H., Stein, R. J., and Ayres, J. C. (1950). Amer. J. Obstet. Gynec., 59, 404.

Sabin, A. B. (1941). Bact. Rev., 5, 1.

Salaman, M. H. (1946). British Journal of Venereal Diseases, 22, 47.

Schaub, I. G., and Guilbeau, J. A. (1949). Bull. Johns Hopk. Hosp., 84, 1.

Smith, W. E., Hillier, J., and Mudd, S. (1948). J. Bact., 56, 589.

Smith, P. F., and Morton, H. E. (1951a). Ibid., 61, 395. - - (1951b). Science, 113, 623.

Szabó, L. (1951). Nature, Lond., 168, 171.

Tulasne, R. (1951). Rev. Immunol., Paris, 15, 223.

Wallerstein, R., Vallee, B., and Turner, L. (1946). J. infect. Dis., 79, 134.

Warren, J., and Sabin, A. B. (1942). Proc. Soc. exp. Biol., N.Y., 51, 24.

Willcox, R. R., and Findlay, G. M. (1949). Brit. med. J., 2,257 .

-,$\frac{}{483}$, and Henderson-Begg, A. (1947). Ibid., $1,483$.

Williams, S. (1946). Med. J. Aust., 1, 693. 